\title{
Exploring Inclusive Developments of Water Supply Management in Urban Informal Areas - Case studies from Mumbai and Nairobi
}

Jia Yen LIM, Department of Architecture and Civil Engineering, Toyohashi University of Technology, Toyohashi-shi, Japan

Haruka ONO, Department of Architecture and Civil Engineering, Toyohashi University of Technology, Toyohashi-shi, Japan

\begin{abstract}
This study examines how the development of water supply management happens over time in distinct types of informal areas in Mumbai and Nairobi. The financial differences and political barriers in both cities, together with the vast diversity factors, development patterns, and challenges of each study area show that reconsidering different approaches is significant in developing more inclusive paradigms in water provision in informal areas. Relevant to these concerns, this study aims to clarify water practices and explore inclusive ways of developing water supply management through the analyses of water provision modes and network systems in each study area. A series of field studies on the type of water sources and facilities, parties involved in water practices, and characteristics of water development was performed in six case studies (i.e., three in Mumbai and three in Nairobi) from 2014 to 2019. The main findings of this study show that an unconventional informal tenure system constrains the settlement typology and development of the physical access of service facilities in study areas. Moreover, the different measures taken by Mumbai and Nairobi in providing water supply to informal areas result in an unequal path for water development and various vulnerability levels. Therefore, we argue that the mixtures of policy-and practice-rooted practices ensure a more inclusive water development because they would lead to the sociotechnical arrangements of the technical system and institutional arrangements that better fit the local conditions characterized by different spatial structures and social variables.
\end{abstract}

\section{Keywords}

Water scarcity, Informal settlement, Water supply management, Mumbai, Nairobi

\section{Introduction}

The adequate supply of safe drinking water is universally recognized as a basic human need. However, many challenges remain in terms of securing water for millions of people in the developing world who do not have ready access to adequate and safe water supply. Despite the advancement made in the past 25 years to improve people's access to water and sanitation, the WHO-UNICEF Joint Monitoring Programme for Water, Sanitation and Hygiene reports that 844 million people still lack access to safe water (WHO \& UNICEF, 2017). The process of ensuring access to safe water is especially challenging in informal areas, given that they are generally considered to be characteristic of low-income settlements with illegal occupations, and their growth has usually exceeded the ability of governments to provide these essential 
services (UN-Habitat, 2003; Mitlin \& Walnycki, 2020). This results in the creation of insecure "informal" water distribution systems that may increase water-borne disease risks (Subbaraman et al., 2013).

Recent international agreements, such as the Sustainable Development Goals and the New Urban Agenda, have laid out paths coordinating universal principles and local knowledge and priorities for the transformation of these urban informal areas into serviced, formal neighborhoods (Habitat III, 2016; United Nation, 2020). The importance of water services toward the vulnerable groups living in informal areas is highlighted by their inclusion in Sustainable Development Goal (SDG) 6 for "Clean water and sanitation" as targets 6.1 and 6.2 that aim to "achieve universal and equitable access to safe and affordable drinking water" and "adequate and equitable sanitation and hygiene for all" by 2030 (UN General Assembly, 2015). Although many governments and organizations have been putting effort toward improving the water scarcity condition in informal areas, financial differences and political barriers, together with the vast diversity factors, development patterns, and challenges, make the outcomes different. For example, in India, the government considers the classification of informal settlements as notified or non-notified slums in service provision (Murthy, 2005). Notified slums have a fair degree of access to basic amenities, including water, toilets, streetlights, drains, and connecting streets, whereas non-notified slums have poorer levels of service access (Bhide, 2009; Subbaraman \& Murthy, 2015). In Kenya, instead of focusing on providing water access through the water department and agencies, Nairobi's county government is taking steps to formalize informal water vendors as a means of providing more people with water, regardless of the informal areas' status (Boakye-Ansah et al., 2019). However, how the water scarcity condition can be improved in a particular informal area, by considering the complex inter-and-intra urban variabilities of water development, has received relatively little scholarly analysis. Therefore, to contribute to our understanding of these complex decisions and outcomes, this research focuses on two well-known cities with slums, Mumbai in India and Nairobi in Kenya. Six case studies are examined (i.e., three in Kenya and three in India), demonstrating a range of legislative and physical upgrading approaches.

This study aims to examine the water practices in each study area and investigate the possibilities of inclusive developments of water supply management in informal areas. We focus herein on analyzing the water supply modes and network patterns of water practices in each area and compare the water development approaches within both cities and study areas. We also aim to reconsider more inclusive paradigms by investigating and conceptualizing the relationships of formal and informal practices, as well as flexibility in water governance, settlement typology and slum types (status), in the redevelopment of informal areas to better fit the sociotechnical and institutional arrangements in developing cities.

\section{Growth of informal settlements}

The growth of informal areas is a global phenomenon accompanying the growth of urban populations. UN-Habitat presently estimates that $25 \%$ of the world's urban population lives in informal settlements, with 213 million informal settlement residents added to the global population since 1990 (UN-Habitat, 2013b: 126-8). However, the growth and developments of informal settlements might be contrasting from region to region as they are not a singular process but differ with different relations with the formal city along with differences of topography, climate, culture, materials, economics and politics (Dovey \& King, 2011).

Informal settlements first emerged in Mumbai in the 1930s when the city was facing an acute housing crisis. During that time, slums emerged as extensions of former fishing villages that are often sites of undesirable economic activities. After independence, increasing waves of poor migrants were pulled to the city by economic opportunities and improved life chances. A combination of several factors, including a severely limited supply of land (private and public) and a sluggish housing activity, resulted in the 
annual shortfall of some 45,000 housing units per year in the 1970 s through the mid-1980s. This shortage was particularly acute in the lower-income groups (MMRDA, 1996). All these factors accompanied by a soft state meant that slum growth was inevitable. The growth of the slum population in Mumbai was the sharpest in the 1970s and characterized by severe droughts in a large part of the Deccan Plateau, bringing in distressed migrants to cities in search of livelihood. This migration pace has leveled off in the recent years, but is still higher than the growth of the overall city population. According to the most recent census conducted in 2011, the slum population comprised 49.38 percent of the total population in Greater Mumbai (Census of India, 2011).

In Nairobi, informal settlements existed before 1960, but it was until in the 1960s and 70s, after the exit of the colonial government, that they enlarged, densified, and proliferated (Amnesty International, 2009; Pamoja Trust, 2009). The locations occupied by the first informal settlements included workers' camps for colonial settler farms, undeveloped land near big farms, idle government or city council land around industrial areas, relocation sites issued by the government to squatters and victims of war, and idle private lands (Matrix Development Consultants, 1993). Confronted by the challenges of poor planning and inability to provide affordable housing, the government could not control the expansion of settlements and emergence of new ones, which led to the sprawl of informal settlements to riparian reserves, refilled quarries, dump sites, and land under high-voltage power lines (Pamoja Trust, 2009). After independence in 1963 and after Africans were released from the movement restrictions imposed on them, Nairobi absorbed people from rural areas seeking job opportunities, thereby expanding the housing needs in Nairobi. Consequently, Nairobi experienced a sharp rise in the number of its informal settlements in the 1970s. UN-Habitat estimates indicated that between 60 and 70 percent of the Nairobi city dwellers live in slum settlements (UN-Habitat, 2016; APHRC, 2014).

\section{Challenges of water provision in informal areas}

Multi-stakeholders face many challenges in the development of environmental infrastructures in informal areas. The first and primary challenge is the technical difficulties of infrastructure extensions. Among these challenges are the topographical location of settlements in previously unused land, physical conditions of the settlements marked by a random and haphazard development pattern and overcrowding, and quality of the materials used to build housing units, which are unsuitable for permanent water pipes and taps. Additionally, the lack of tenure for land or housing can pose a significant obstacle to the provision of water services because provision by utilities and extension of water services by local authorities often depend on the existence of a legal tenure for property (Murthy, 2015). These two issues are challenging for public policy. Overcoming the difficulties associated with the outlined settlement conditions requires the relocation of slum dwellers to more suitable areas and the enforcement of housing standards. Granting full tenure to tackle the problems associated with the insecurity of tenure may raise property prices and result in the development of new slum areas. Dwellers may sell their plots and squat elsewhere. The policy may benefit the non-poor, especially property merchants.

Many governments remain hesitant to accept informal areas as an unavoidable reality, incorporate them within urban development plans, or program the resources necessary to provide essential services, even where such funds are available. In the example of Mumbai, legislation and policies changed in the 1970s to viewing the slum as needing housing solutions. However, issues still exist in grouping slums as "legal" or "illegal." The relevant state law, which is the Maharashtra Slum Areas Act, defines a slum as an area lacking basic services that is "unfit for human habitation." The state government has the power to "notify" a slum, which gives it a form of legal status and makes it eligible for rehabilitation through a slum rehabilitation scheme. Moreover, slum dwellers who have been living in a slum before 2000 are now 
considered to be "protected occupiers," which gives them extra protection from eviction. Slum dwellers who began living in a slum after 2000 do not have the same protections and are considered "illegal" or "non-notified" Similarly, slums located on the central government land are also non-notified, even though the central government of India has several schemes designed to rehabilitate slums and expand access to basic services in all slums, regardless of legality (Subbaraman \& Murthy, 2015).

\section{Methodology}

We applied a case study methodology focused on the research question to contribute to our understanding of the water supply management in informal areas, as well as the ways of exploring inclusive water developments. At first, six neighborhoods with distinct typological backgrounds were chosen, covering a wide variety of informal areas in Mumbai and Nairobi. The criteria considered in Mumbai were land tenure and local governance; in Nairobi, morphologies and development patterns assumed to affect the water provision development in informal areas.

The selected study areas in Mumbai were Dharavi Koliwada, which is an urban village, Shiv Shakti Nagar, which is a notified slum cluster, and Ana Nagar, which is a non-notified slum neighborhood. Dharavi Koliwada is an urban village that serves as one of the several preserved Koli neighborhoods scattered all over Mumbai. It gained the legal status of gaothan (urban village) in 2014, under which the Koli community has been formally recognized as the landowners of Koliwada. This legal status does not only ensure the security of land tenure, but also enables the village to be mandated to self-develop their land, as opposed to the formal development that happens in the rest of Mumbai. The government has been relied on for wider public development, such as the upgrade of water and sanitation services. The community has also been working in association with the Municipal Corporation of Greater Mumbai (MCGM) to provide facilities and ensure infrastructure management in the area. Shiv Shakti Nagar is a notified slum cluster located in the middlemost part of Dharavi. As part of the notified slum of Dharavi, it has been undergoing slum regularization by the authorities and connected to public water provision since the 1970s. Ana Nagar is a neighborhood in the non-notified slum of Kaula Bandar located on a wharf on Mumbai's eastern waterfront. This non-notified neighborhood faces additional legal barriers to accessing resources because it is located on land that does not belong to the city government.

In the case of Nairobi, three areas in Mukuru Kwan Ngenja slum were selected according to their distinct physical and development patterns: MCC, Jua Kali, and Sisal. Sisal, which is the oldest village in Mukuru Kwa Njenga, started development as early as the 1950s and has an unplanned layout with various plot sizes and shapes. Meanwhile, Jua Kali and MCC have planned layouts with 33 by $66 \mathrm{ft}$. uniform strip-shaped plots along a straight road with a width of approximately $8 \mathrm{~m}$. The size and the shape of the structures are generally the same as those of the plots; thus, Sisal has structures in various sizes and shapes. On the contrary, uniform strip-shaped structures are more common in Jua Kali and MCC. MCC, which is the latest in development, is leading to the development of apartments, tenements, and flats and can be considered as a "formal-looking" settlement instead of a "slum" (Ono, 2020).

A series of field studies on the type of water sources and facilities, parties involved in water practices, and water development characteristics was performed in Nairobi in 2014 and in Mumbai in 2019. A survey on the type of water sources and facilities was conducted by observation and measurement, focusing on the location of sources, functioning availability and reliability, and physical network connections. A survey on the parties involved in water practices and the water development characteristics was conducted through in-depth interviews with community leaders, local developers, facilities owners, and residents. Instead, of studying from a quantitative survey, we focused herein on random qualitative surveys and cluster samplings to gain more accurate and detailed data in vastly diverse informal areas. 


\section{Case studies on water supply managements and developments}

\subsection{Water supply and sources in the study areas of Mumbai}

The water supply in the informal areas in Mumbai became an obligatory duty of the MCGM after the Bombay High Court ordered the city government to extend water supply access to all residents, including those who live in non-notified slums in December 2014 (Subbaraman, 2015). However, given the highly dense and undulating character differences in each area, making water accessible to all informal areas using the localized decentralized water delivery system through water pipelines remains a technical and physical nightmare for the authorities. Moreover, the reluctancy of the MCGM to provide water connection to the residents living in non-notified slums had caused the governing regulatory system to fail in ideally ensuring every household of water provision and diverse distinctions in the serviceability and social life of the water infrastructure and services in different informal areas. Thus, the incomplete formal system in informal areas has direct consequences to the myriad examples of water provision initiatives in Mumbai.

The selected study areas are distinct in terms of their statuses and legalities of being informal areas, which have resulted to the unequal environmental infrastructures and services in these informal areas. Consequently, ranging from a regularized system to small enterprises, water security indicators, such as the sustainability and cost of provisions, are different in areas. For example, the area with a regularized system of provision tends to have a constant tariff, while the area that relies on small water enterprises varies in cost of water. Table 1 summarizes the differences in the development of infrastructure and water provision modes of these three areas.
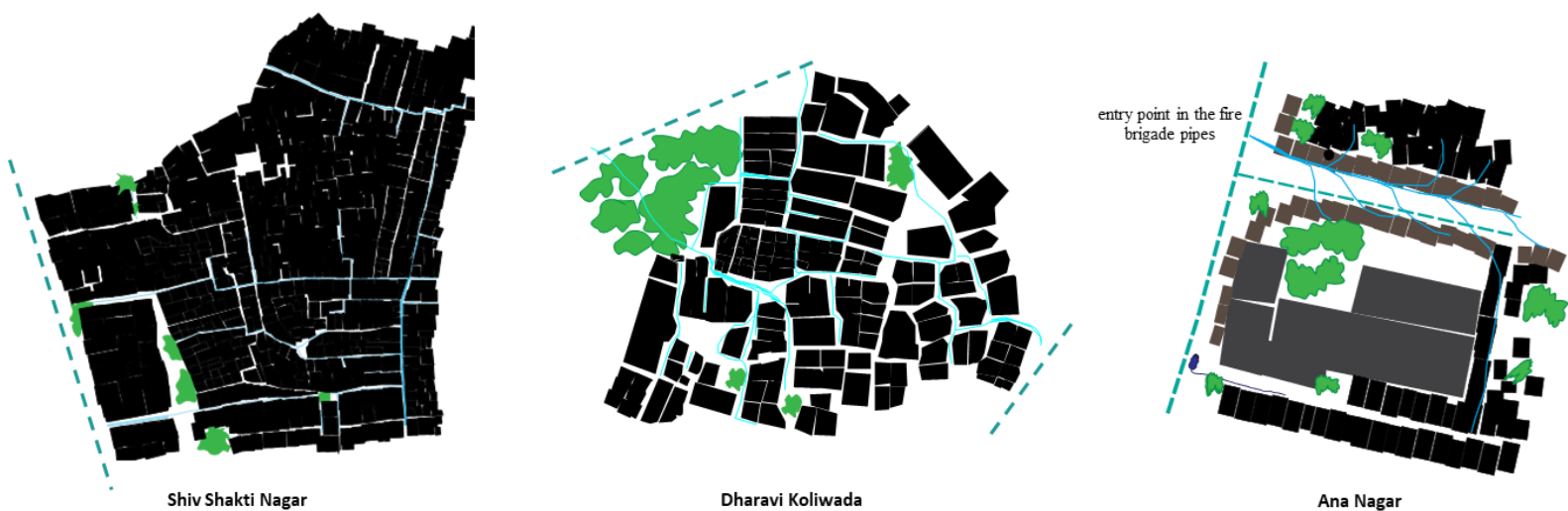

Dharavi Koliwada Ana Nagar

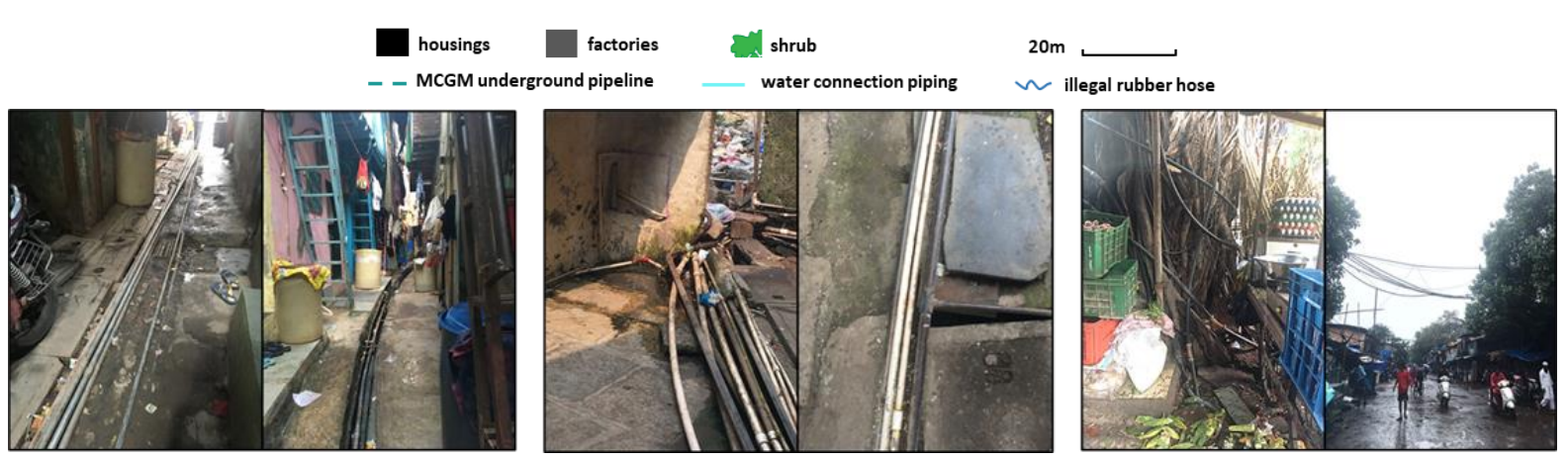

Figure 1. (Above) Water piping and supply connections in the neighborhoods of Shiv Shakti Nagar, Dharavi Koliwada and Ana Nagar. (Below) Structural conditions of water piping. Source: authors' mappings and photos as parts of the results from site surveys in Mumbai, 2019. 
Table 1. Water sources with the ideologies of production and delivery in the case study of Mumbai.

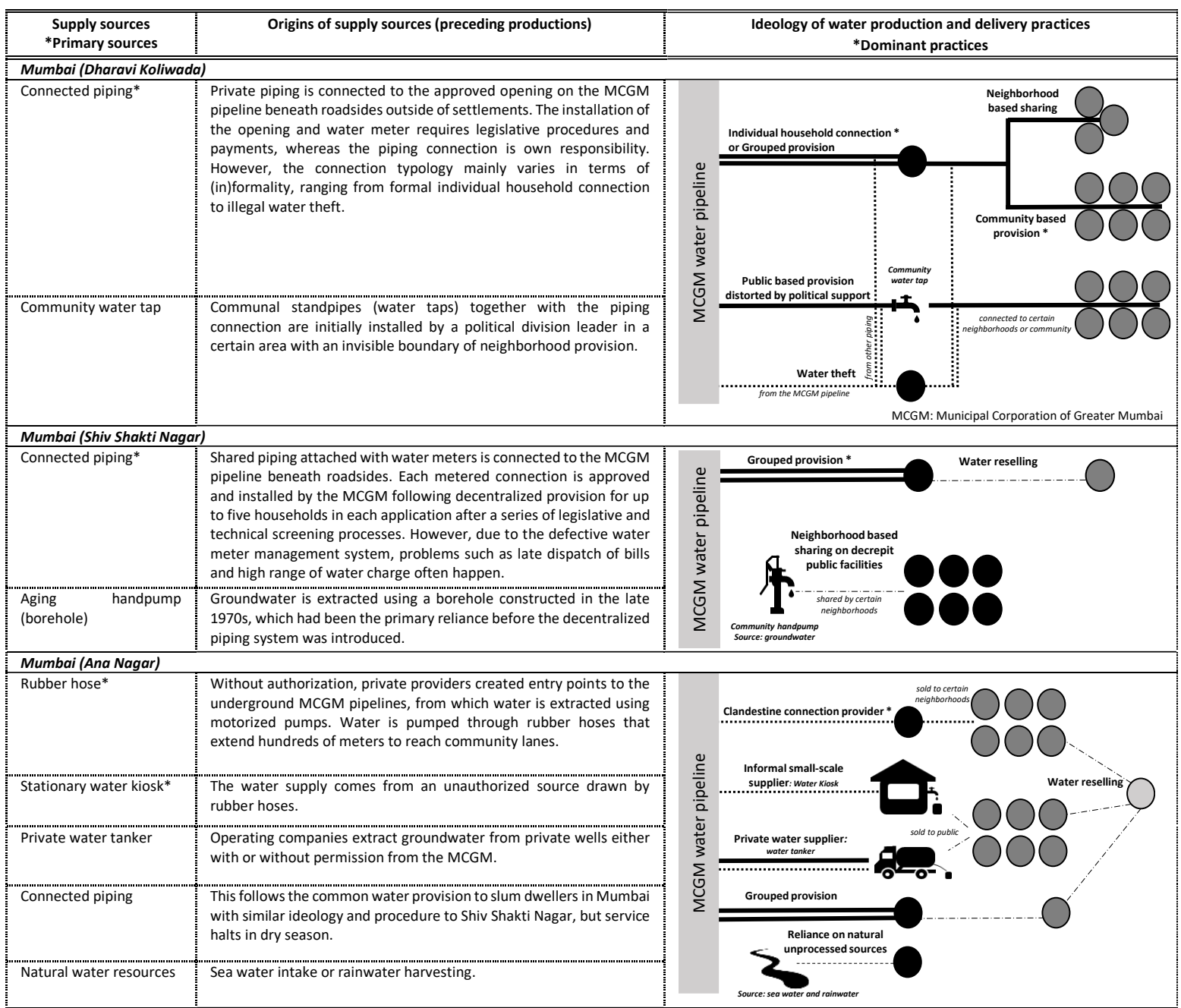

In the notified slum cluster of Shiv Shakti Nagar, water is released by the MCGM in the mornings for approximately $2 \mathrm{~h}$ at varying times in different areas. Small pipes can be easily seen branching out of bigger pipes at the roadside. These straightly aligned pipelines carry water into the inner part of the slum area with a higher population density; hence, its sustainable water-supplying performance depends on the water pressure and the proximity of the house to the main water pipe. Almost all residents acquire water supply by applying to the connection scheme that regularized the water supply system in the notified slum through the decentralized system first introduced in JNNURM (CEPT, 2014). Under these schemes, five households have to come together to obtain connection for water from the MCGM. Each house ends up spending 3500 Rupees for this kind of shared connection. This is the only efficient way of getting connected to water provisions in Shiv Shakti Nagar; thus, less illegal water distribution exists in the community.

In Dharavi Koliwada, the water demand by residents has been met by the MCGM's water connections and a community-based scheme. Based on our three random quantitative surveys, up to $85 \%$ of the interviewed residents from Dharavi Koliwada are satisfied with the water supply they have (i.e., an average duration of $4 \mathrm{~h}$ per day in the morning). The cost of water services every month varies according to the household's connection. However, we found that the cost was Indian rupees (INR) 250. Excess supply and affordable water has seen water waste and ignorance of leakages. As a formal method of supplying water, Figure 1 (will be added) shows a messy, spaghetti-like array of pipelines connecting the village from the roadside, while complex informal or semi-informal water pipeline networks have been 
incrementally built by local plumbers and residents as a complementary practice in the neighborhood. These water supply networks, with physically high and flexible arrangements of steel and polyester pipelines, were formed for two reasons: 1) ownership of a high individual or communal land ownership to this inherited land; and 2) existence of the informal community-based water management system.

The water crisis problem emerged as the biggest concern of the residents in Ana Nagar among the three study areas. The government has been refusing to provide a formal piped water connection to the slum residents here; hence, they have to rely on informal water provision. They are not provided with clean water supply by the government and the water they get through informal ways is not clean. Approximately $80 \%$ of its residents have some form of disease according to the research conducted by PUKAR (Subbaraman \& Murthy, 2015). Households normally store the water they collect in large blue plastic drums with a capacity of $\sim 250 \mathrm{I}$. The water will be used for 2 or 3 days before the next collection. This informal water distribution system is vulnerable because local officials occasionally raid and confiscate motors tapping into the fire brigade pipes, cutting off the water access of Ana Nagar's residents. Such episodes of a "system failure" occur a few times a year. When this happens, most Ana Nagar residents roll large storage drums for at least $1 \mathrm{~km}$ and as far as $2 \mathrm{~km}$ to access taps in the next closest community, while others obtain water from private tankers.

\subsection{Water supply and sources in the study areas of Nairobi}

In Nairobi, the provision of water and the development of related infrastructures are the mandates of the two main relevant agencies: the Nairobi City Water and Sewage Company (NCWSC) and the Athi Water Services Board (AWSB). Even though the efforts of the two have been amplified through partnerships and collaborations with various other players in the non-governmental and community sectors, connections to the informal settlement were initially illegal. However, through a community-based partnership with service providers, the minimum level of supply was provided to the residents in informal settlements where common water chambers as connection points were allowed to be connected by individual users. With time, the AWSB supplemented this with a system of water kiosks following the main circulation spine. They later then amplified services through collaborations and partnerships with NGOs and CBOs and development partners like the World Bank and the European Union. Unlike the implication of the regulatory system in Mumbai, the water provision in the informal settlements in Nairobi remains a result of a mixture of formal and informal interventions by various actors cutting across the public, nongovernmental, and community sectors. It is common that beyond the formal category lies another significant bracket of users who are not direct clients of the NCWSC, but are often illegal connections largely for commercial purposes, such as water vendors or small water enterprises (SWE).

Due to the lack of government-operated water supply, access to clean water is a challenge for Mukuru residents. According to Muungano Support Trust (MuST) enumeration data, 97\% of the residents do not have a water connection in their homes, resulting in the majority of residents getting water from informal water providers who control the water provision through laying water pipes and kiosks in the settlement. These pipelines usually run in line with open sewers and garbage dumps and are frequently poorly maintained, thereby resulting in severe quality issues. The water supply dominates this informal clientelization; hence, Mukuru residents have no choice, but to pay for water with an average cost ranging from 3 to $10 \mathrm{ksh}$ per 20 I jerrican, which can sometimes be as high as four times more than the average water price in other urban areas in Nairobi. The distinct development patterns of each study area have also resulted in heterogeneous informal providers and their diverse ties to formal actors. This not only makes the water provision system and its operation modes vary across the three study areas (Table 2), but also conveys a fitting site for uncovering new facets of informality in urban service provision. 


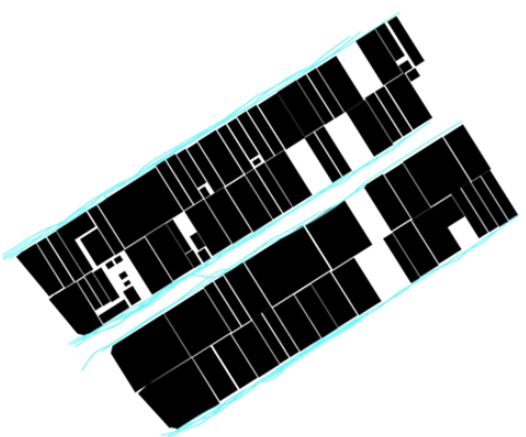

MCC

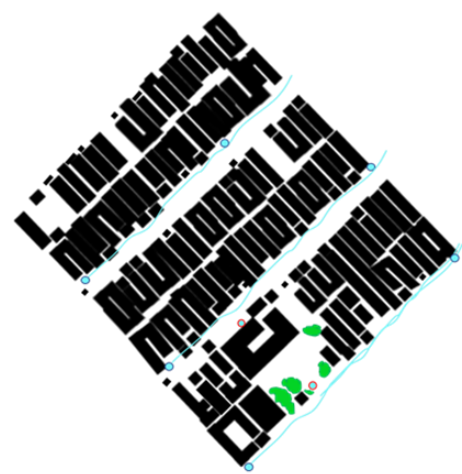

Jua Kali

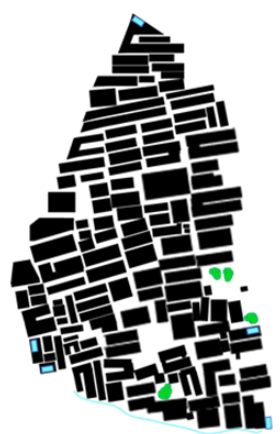

Sisal

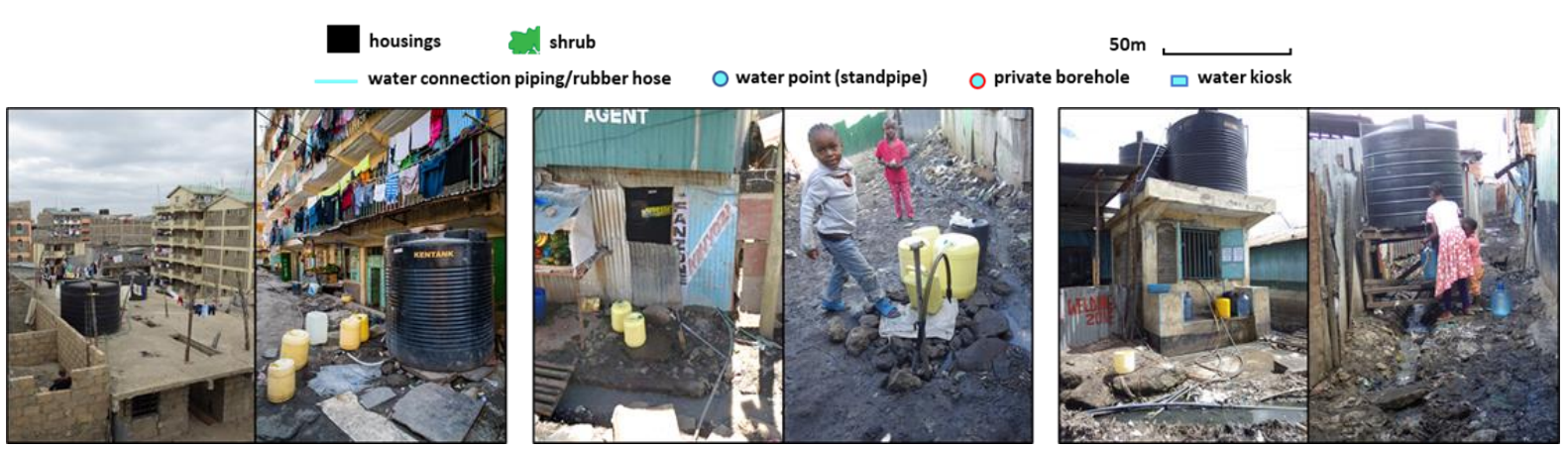

Figure 2. (Above) Water supply facilities and connections in the neighborhoods of MCC, Jua Kali and Sisal. (Below) Structural conditions of water facillities. Source: authors' mappings and photos as parts of the results from site surveys in Nairobi, 2014.

Three study areas are similar in that the residents rely on the SWE to access water supply, even though their operation system differs in terms of connection extends, provision scale, and management. The water provision is usually dominated by low-quality, often-predatory informal service providers locally called "cartels" (Corburn et al., 2017), who mostly access NCWSC supplies through illegal connections. They gain water supply through various means. They either buy water from the publicly owned municipal water company at a highly subsidized rate and sell it in a quasi-formal way or own illegal connections made by breaking into the NCWSC pipelines from which they steal water with impunity and then sell it from their water points or kiosks. The relation of these SWE with the formal actors differs according to the way they obtain water provision; thus, the relationship between the SWE and the staff of the NCWSC is normally confrontational and characterized by mutual distrust and dislike. The situation has developed into a continuous battle with frequent disputes and conflicts that often end in threats, acts of violence, and complete disconnection of Mukuru from the water supply network.

Among the three study areas, Sisal is the more vulnerable area facing water scarcity. Although the social and economic characteristics of the area make it the least developed with an unplanned settlement layout, the prevailing settlement typology is another fundamental implication on the water service delivery within the area. Compared to MCC and Jua Kali, Sisal is categorized as an organic area, where the dendritic character of available access paths where off the main circulation spine, the inner roads quickly degrade into often very narrow paths, of irregular width, and twisted following left-over space between irregularly positioned building structures. Under such a manifestation of a haphazard spatial layout, the water reticulation that normally follows the road orientation becomes difficult because the piping must be aligned to the twisted and irregular street grid or laid below building structures to achieve straight and more efficient networks. This has affected the reticulation of water services, hampered the levels of supply and the quality of the water supplied, and made the reticulation an expensive affair in addition to making households walk far distances to access water points. This eventually portrays the reason why the 
Table 2. Water sources with the ideologies of production and delivery in the case study of Nairobi.

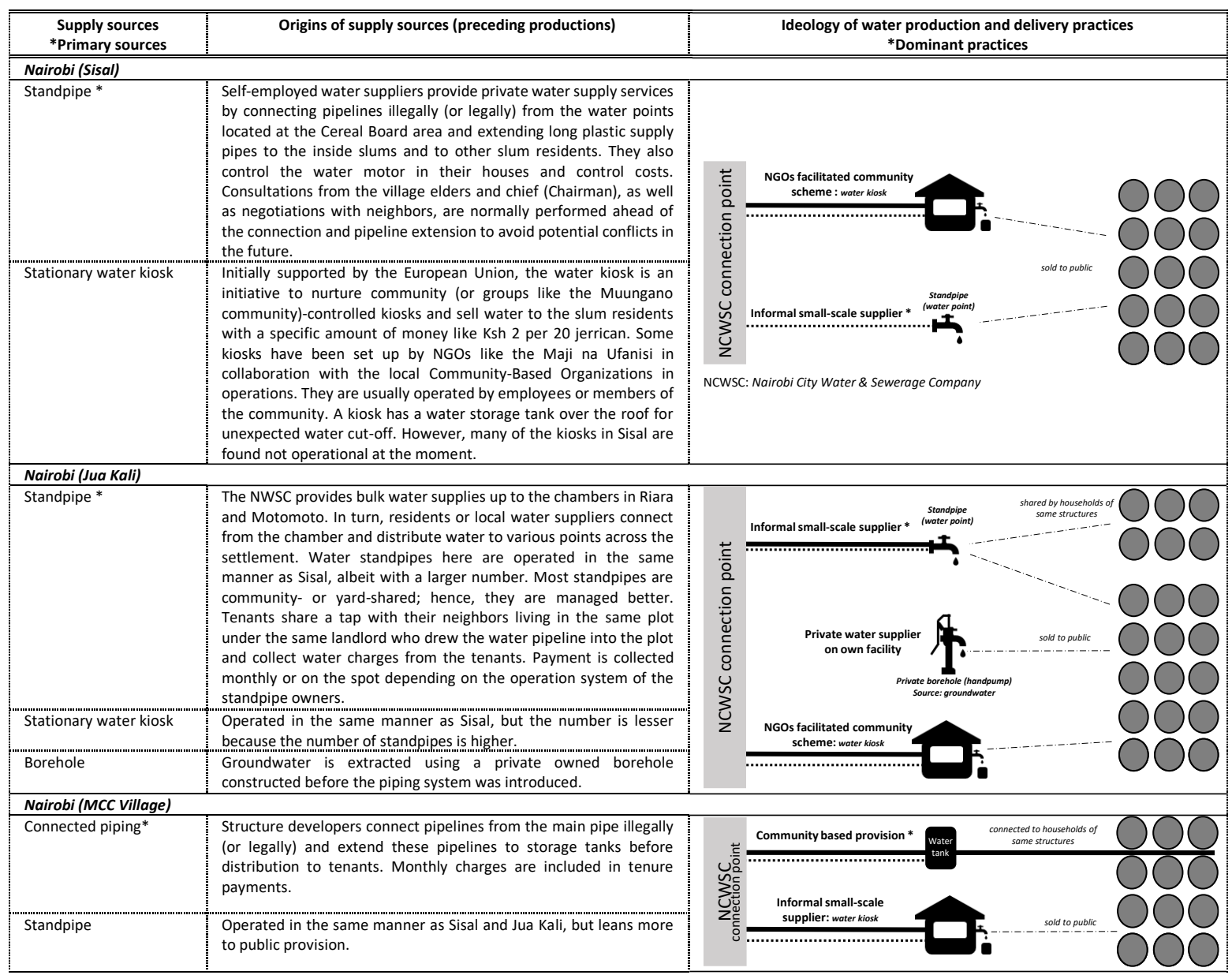

number of water points in Sisal is lesser than that in Jua Kali. Consequently, the water kiosks managed by the local community (e.g., youth groups) have been mainly relied upon for water supply by the community before the number of water taps increased in the recent years. However, due to poor maintenance, these facilities are always not very operational and cause water scarcity to the community. Due to the lack of secure sources of water provision, residents are sometimes forced to pay unreasonable prices for a jerry can of water and those who cannot afford it have to seek for other alternatives.

In contrast to Sisal, Jua Kali, which is a refine area, has a better road or circulation network that allows a higher level of water supply into its neighborhoods, even if it is located at the inner clusters of Vietnam village. Due to this condition, the density of water access points in Jua Kali is higher, where the neighborhood has a closer proximity between the water points. This factor resulted in a higher percentage of reliance on a standpipe compared to Sisal. Additionally, the water provision scale of each water point is different from that in Sisal because a number of water points in Jua Kali is privately owned or yard-shared instead of being part of the public provision. Structure owners or developers have extended the water connection and installed standpipes for the limited target of users that usually make up an average of 12 households who stay at the same block. Private or yard-shared standpipes have better maintenance compared to public standpipes.

Considered as a highly refined area, MCC has a relatively adequate and improved water provision because of better street organization, more permanent structures, and higher street profiles due to the high-rise stone developments in the village. Majority of the high-rise developments in MCC are formally serviced. In many cases, water provision is at the unit/household level, with some units being self- 
contained. This has proven that the settlement patterns described earlier on as "refined" offer opportunity for settlement upgrading using in-situ approaches. The well laid out streets and paths make it possible to design utility networks and circulation patterns. Developers have adopted suitable patterns that allow for densification while facilitating traffic movement. However, one short coming is the amount of space allocated for open areas and recreation, which is a requirement for better quality of human settlement.

\section{Analyses and findings on water developments of study areas}

\subsection{Analysis on the relationships of water governance and technology applied}

While governments and private sectors in developing cities have been concentrating on getting the industrial systems in order in formal areas, the majority of the population in informal areas has to solve water supply problems by themselves. By implication, these alternative forms of services are often private and informal. Wanting to avoid public-private dualism, Bakker (2003) chose to examine the various modes of provision from the angle of industrial versus artisan form and community versus corporate control. Figure 3 builds on a similar relationship grid by Bakker to analyze the differences in the water supply pathways and modes and the water development trends in each study area. It shows the water practice modes identified in Mumbai and Nairobi to illustrate the kind of cooperation or largerscale collective action required to produce each form of service.
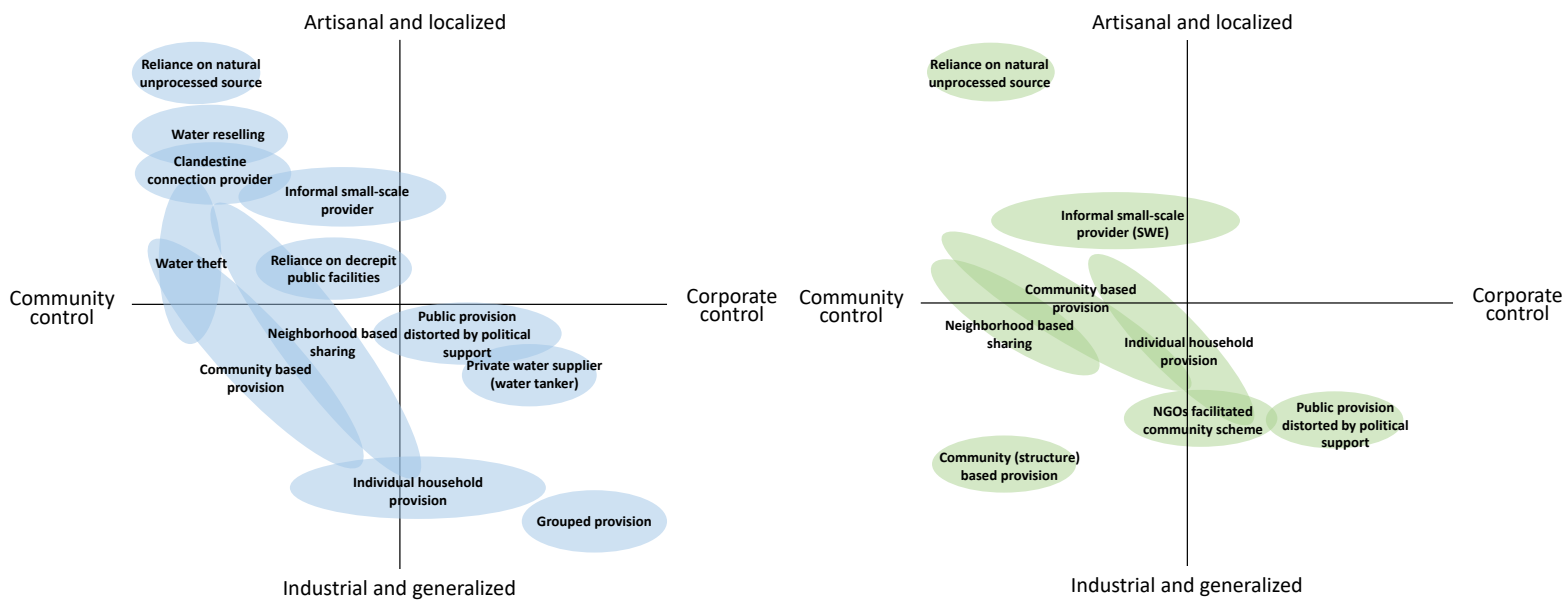

Figure 3. Modes of water provisions in infromal areas of Mumbai (left) and Nairobi (right).

The $\mathrm{x}$-axis of the graph represents water governance, where corporate-community has been applied instead of using the public-private dualism that breaks down when attempting to analyze the water supply provision in informal areas. Toward the right part of the relationship grid, one can see "Corporate control" defined as an organization recognized in law as a "person" characterized by limited liability and bureaucratic hierarchy. In addition to private companies, many governments assume corporate forms (Bakker, 2003). The left part of the figure illustrates "community control," which presumes that the modes of provisioning placed here are well embedded into the community and its customs. As long as groups are sufficiently small, rules for maintenance and use may be informally maintained by social control, and no formal institution is required.

The $y$-axis represents the degree of the water supply technology, where industrial-artisanal is applied to describe the level of the structural connections of the water supply from providers to users. The major difference between the artisan and industrial forms of water production is related to the level of investment and mechanization. Given the investment requirement, it is not by coincidence that the 
artisan modes of production are skewed toward the community side of the figure, while the industrial modes are skewed toward the corporate side. These are not independent variables.

The mode circles are positioned with regard to the different levels of community or corporate control and the different industrial or artisan content of the service production in the informal areas of both cities. Moreover, the circles are not representative of the relative size or importance of the different modes nor of their interdependence or direction of development; instead, the placement of the various modes to the different level of governance and technology is more emphasized.
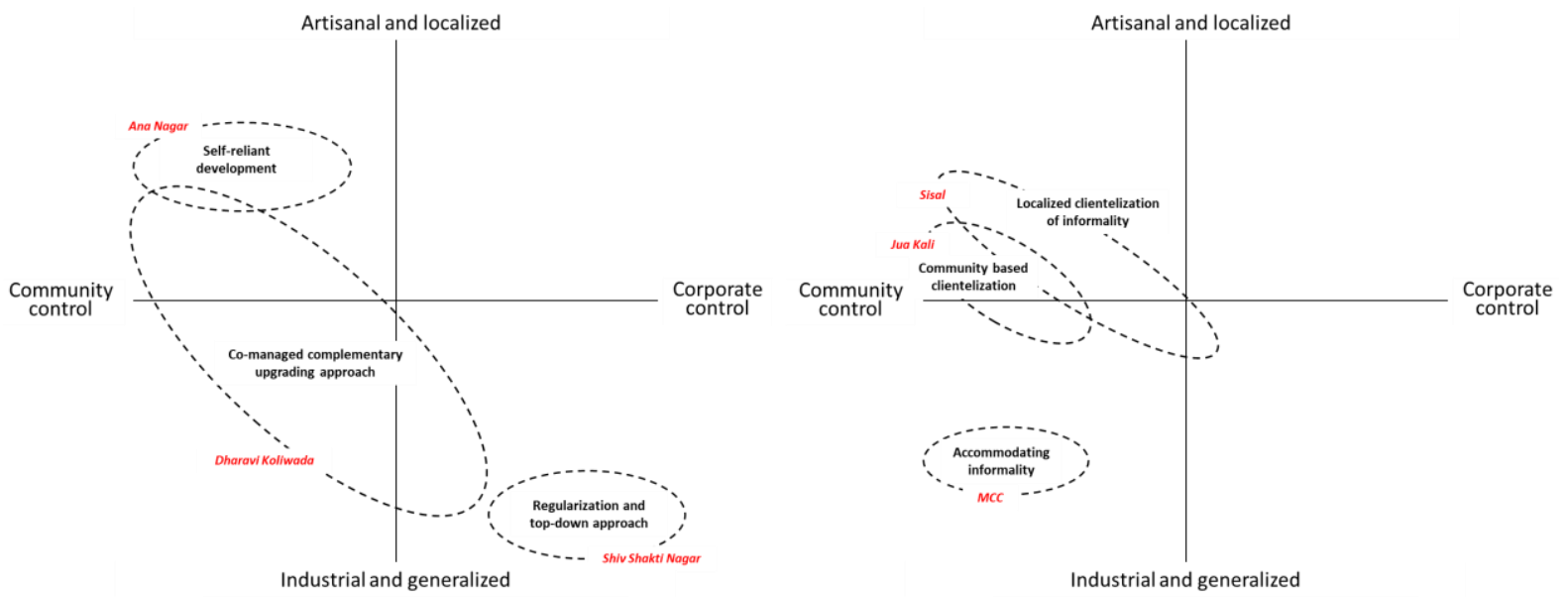

Figure 4. Water development in infromal areas of Mumbai (left) and Nairobi (right).

Refering to Figure 3 , the regions where water practices focus in each area are expressed in the circles in Figure 4. In Mumbai, the regulatory water provision system applied in Shiv Shakti Nagar represents the corporate/industrial modes in the bottom right corner. The regularization and formalization process of informal areas ensures the continuous water supply to the residents through the top-down approach. However, as the regularized system becomes the most heavily relied means of water provision, the influence of water privatization that included community partnerships becomes minor. In contrast to the case of Shiv Shakti Nagar, the water development in Ana Nagar falls on the community/artisan modes in the upper left corner. This implies the reluctancy of the government to provide water supply and allow external donors to further engage in local development. Unlike in Dharavi Koliwada, the lack of social hierarchy within a community resulted in the emergence of community-based privatization in water services. Together with illegal private providers in their clandestine collaborations, the local community has invented a decentralized modal of water production and distribution system to scale up the water provision to majority of the residents in the area. Even though private water tankers occasionally provide water to the area, the local provision is still preferable for its accessibility, convenience, and constant price. In Dharavi Koliwada, the water development ranges from corporate/industrial to community/artisanal as the influence of local hierarchy. Even though the municipal corporation became the main provider of the public water supply, the community association, who is the stakeholder of area developments, remains actively engaged in the community provision. The water service distribution involves both community and individual initiatives; hence, the technology applied in their practices varies according to social and economic factors.

In the case studies in Nairobi, the residents experience water insecurity that indicated differences within the areas. However, the analyzed water development patterns leaned more toward community control when compared to the study areas in Mumbai because the SWE and the clientelization of informal water sectors mainly belong to community-oriented practices. In MCC, which is a highly developed area with the most secure water supply among all areas, the households are mostly formally serviced with water provision at the unit/household level, which resulted in the most industrialized water development 
approach. This also dealt with its high reliance to the unified system provided by local structure developers. Therefore, we describe it herein as a pseudoformal or a quasi-formal approach of water development that imitates the government-led top-down approach and regularized system. The water developments in Jua Kali and Sisal are almost the same in position due to their high reliance on SWE. However, the operation system in Jua Kali is better managed and limited to target users; therefore, it is more community-controlled and industrialized than that of Sisal. Furthermore, Sisal has a similar selfreliant water development condition as Ana Nagar because of its limited access to water sources. It, however, allows the engagement of NGOs in supporting the management of SWE and has resulted in the partial involvement of the external corporate and local community in water development.

\subsection{Analysis of water supply networks}

The water network concept illustrated in Figure 5 analyzes how the water supply reaches users in each study area and how informality works in water provision. The networks depict how the water supply from one chamber can reach the households in informal areas.

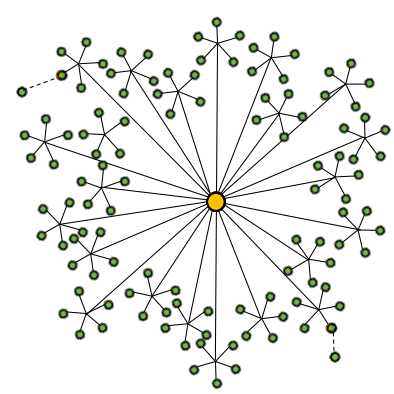

Shiv Shakti Nagar

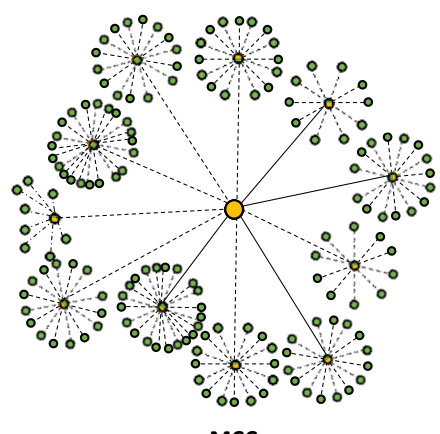

MCC

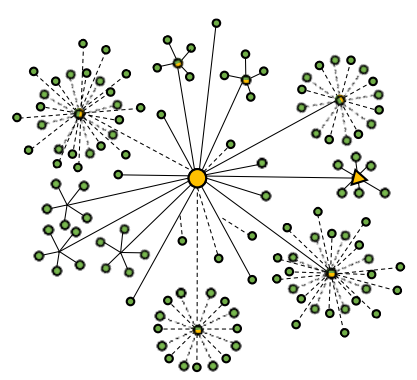

Dharavi Koliwada

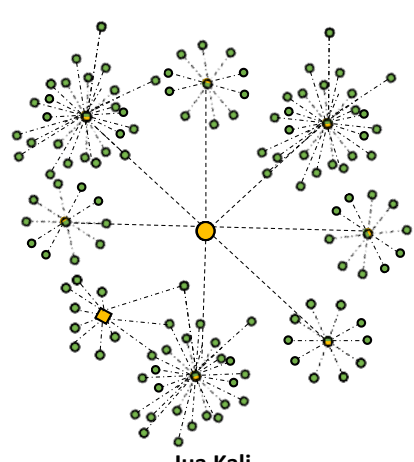

Oother supplier (water tanker) $\Delta$ piped communal facilities - improper/informal piped connection (rubber hose)
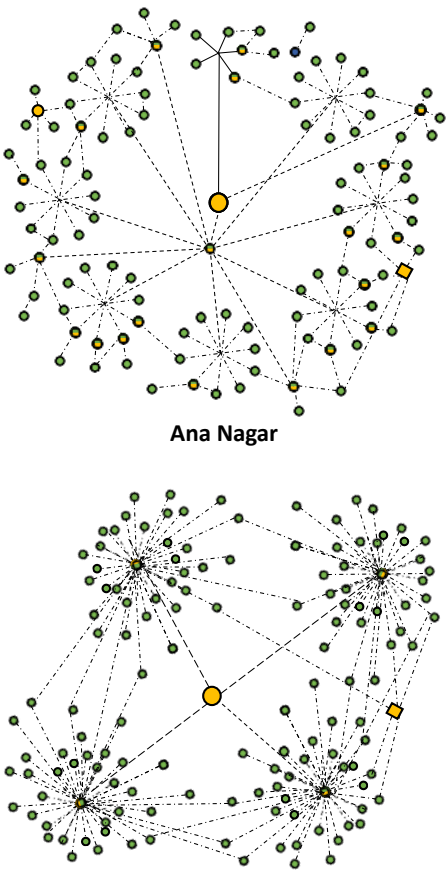

Sisal

o user + secondary supplier ouser -non-physical/non-piped connection

$O$ piped (primary) source $\diamond$ non-piped source
- proper/formal piped connection (steel piping)

Figure 5. Illustarations of water supply networks in informal areas.

In Mumbai, the water supply networks differ due to the classifications of slums according to their recognized status. A notified slum undergoing slum regularization by the authorities, which is the schematic network system in Shiv Shakti Nagar, illustrates a structurally decentralized distribution scheme based on the centralized government provision in a slum cluster. Water is distributed in a homogeneously regularized and privatized system with a coherence of the applied technology and scale. The network system enables wide water provision in a densely populated neighborhood. In the case of Dharavi Koliwada, the development of a water provision network is associated with a relatively old and diverse background of neighborhood development. The high individual or communal land ownership and the existence of an informal community-based water management system have resulted in a coexistence system of a formal primary source of water provision from the government (central node) and a complex community-based scheme that usually occurs in the form of an informal system in each neighborhood. 
The mixture of policy- and practiced-rooted systems or authorized and unauthorized systems has led to the emergence of complex and hybrid situations. Most of the time, the mixed system successfully results in an innovative adaptation to the local conditions and an increase in the coverage of water provision to the socially diverse community by providing choices (e.g., installation cost and consumption price) to individual households based on social trust and agreements. On the contrary, in Ana Nagar, which is a neighborhood of a non-notified slum deprived of access to basic services and amenities, the water provisions and services are provided through a combination of a decentralized distribution system and a weak relationship to the government supply (central node). Non-notified slums generally lie outside the coverage of the formal system, which, in most cases, are restricted to a relatively small core. The informal or simply "practice-rooted" practices are at best overlooked and, at worst, resisted by the set of policies, regulations, and resources that structure and support the formal system.

In the study areas in Nairobi, the water networks imply the results of the SWE operation that has made a larger provision scale compared to Mumbai. However, the water supply distribution to households involves fewer infrastructures like water piping. That is, the cases in Nairobi show less investment into the lower-hierarchy parts of the supply system than that in Mumbai. The lower-hierarchy pipes constituting the local distribution system are still underdeveloped both in absolute and relative terms. The cases in Nairobi are also characterized by a less decentralized and larger provision scale because of the lesser number of decentralized facilities. MCC has a developer-led water provision similar to Shiv Shakti Nagar in Mumbai, but its dendritic pattern has less branches and a larger provision scale at the end of each branch of the water supply. On the contrary, the water network in Sisal is similar to the clandestine water provision in Ana Nagar. Both sides have a rather distributed network system compared to the other cases in the area. Sisal, however, has a more flexible, but less reliant relationship between the supplier and the users. The increases in the number of water sources and the selection of water supply means will ensure better water accessibility and quality of provision to the area. Albeit having more private and community-shared water facilities that provide more managed and reliable sources compared to Sisal, Jua Kali might be developed into a distributed pattern once failure happens to each provision.

Overall, both cases in Mumbai and Nairobi have shown common trends, that is, an area with a more vulnerable water provision tends to have a more distributed water network pattern to ease the water scarcity. The more regularized the area, the less flexible the water provision system is and the firmer the relationship built in the areas is. Except for the case of Shiv Shakti Nagar, the hybrid service provision modalities and co-production of water services consisting of formal and informal water practices are a common phenomenon in informal areas.

\section{Conclusions}

The results of our research on the water supply management of informal settlements are drawn as follows:

1. The different approaches taken by Mumbai and Nairobi in providing water supply to informal areas result in different paths of water developments in terms of transforming vulnerability into resilience. In Mumbai, the relation formed aligns to the continuums of formal-informal and collective-individual (Figure 6), which has to be dealt with the level of engagement of authorities in public water provision toward each area. On the contrary, in Nairobi, the water supply domination through informal clientelizations by structure owners, developers, or community water providers has implicated a "community-control" provision system. Thus, we define it herein as the continuum of pseudoformal and quasi-informal development approaches instead of formal-informal. Both case studies showed that the conditions in the informal areas are physical and statutory manifestations that create barriers to human 
and social development. Therefore, more inclusive paradigms in the redevelopment of informal areas must be reconsidered, in which all actors involved should first overcome the apathy and lack of political will that have been a barrier to the water supply progress.

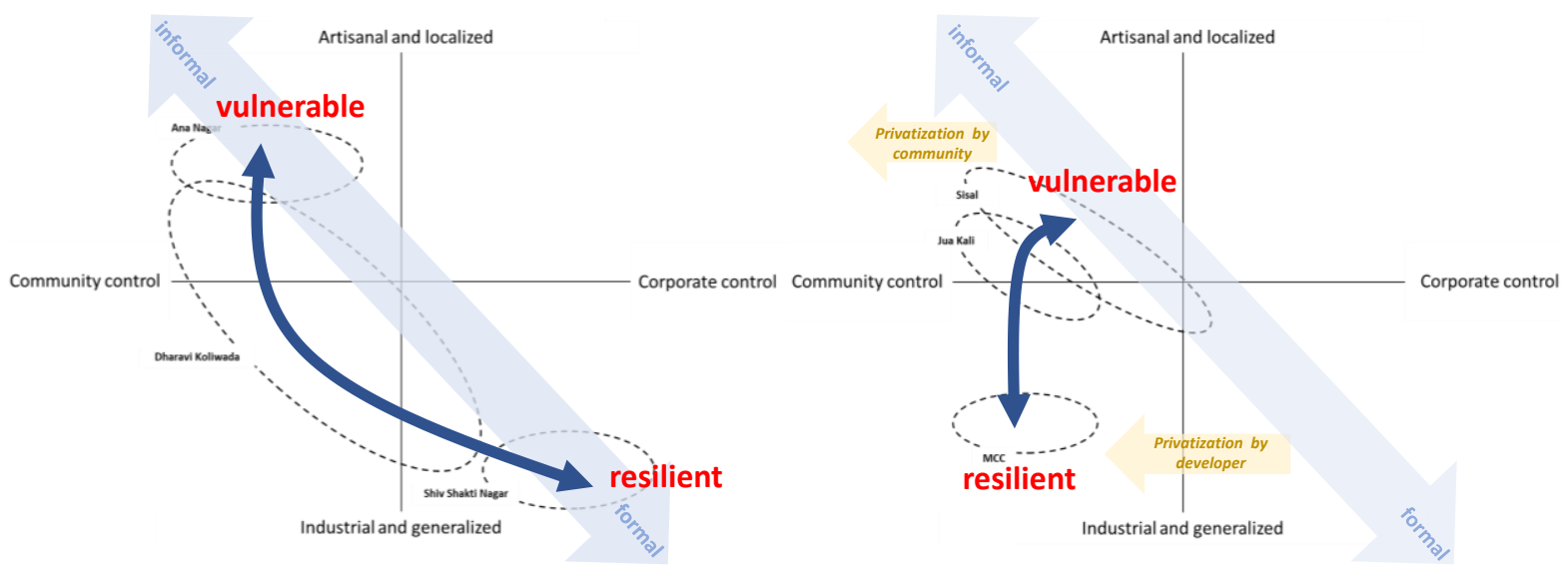

Figure 6. Water development approaches in informal areas: Mumbai (left) and Nairobi (right).

2. The cases in Mumbai illustrated that the regularization of water practices brings a more sustainable supply to the residents. However, the cases of non-notified slums and urban villages proved that the hybrid provision modes and co-management have formed decentralized and distributed water networks that help improve resilience toward the water scarcity. The mixtures of policy- and practice-rooted practices would lead to sociotechnical arrangements of the technical system and institutional arrangements that take best features from both formal and informal systems to better fit the local conditions characterized by different spatial structures and social variables.

3. Informal tenure is not uniform and affects settlement typology and basic services in various ways. The study of Nairobi established that the prevailing land tenure in Mukuru informal settlements has implications both on the settlement typology and service provision. Secure tenure is the precondition for a better settlement organization and development because it is always associated with increased investment incentives and improved access to public services like water supply. In contrast, an unconventional tenure system constrains the development of informal areas and the physical access to service facilities. Investment into the lower-hierarchy parts of the supply system and formalizing the SWE with the cooperation of developers are necessary to provide a more inclusive system to the residents.

This research clarifies the diversity of water development patterns in informal areas by analyzing the effects of inter-and-intra urban variabilities on water supply modes and network patterns of water practices from the case studies of Mumbai and Nairobi. Further study is needed in identifying more comprehensive paradigms and strategies in sociotechnical and institutional arrangements to conceptualize inclusive development approaches of water supply management in informal areas.

\section{References}

Akiba Mashinani Trust (AMT); University of Nairobi; Strathmore University; Katiba Institute. (2014) 'Mukuru: situation analysis report', IDRC, unpublished.

Amnesty International (2009). The Unseen Majority: Nairobi's Two Million Slum-Dwellers, Amnesty International Publications.

APHRC (2014) Population and health dynamics in Nairobi's informal settlements: report of the Nairobi Cross-sectional Slums Survey (NCSS) 2012, African Population and Health Research Center, Nairobi, Kenya. 
Bakker, K. (2003) 'Archipelagos and networks: urbanization and water privatization in the South', The Geographical Journal, 169(4), p328-341.

Bhide, A. (2009) 'Shifting terrains of communities and community organization: Reflections on organizing for housing rights in Mumbai' Community Development Journal, 44(3), 367-381 [online] Available at: http://www.jstor.org/stable/44258150 (Accessed: 15 October 2020)

Boakye-Ansah, A.S.; Schwartz, K; Zwarteveen, M. (2019) 'From Rowdy Cartels to Organized Ones? The Transfer of Power in Urban Water Supply in Kenya', Eur J Dev Res 31, 1246-1262 [online] Available at: https://doi.org/10.1057/s41287-019-00209-3 (Accessed: 3 October 2020)

Census of India (2011) 'HH-6: Slum Households by Main Source of Drinking Water and Location, Tables on Houses, Household Amenities and Assets', Census 2011, Ministry of Home Affairs, Government of India.

CEPT University (2014) 'Water in Slums of Mumbai-view from the field', CEPT University [online]. Available at: https://pas.org.in/Portal/document/PIP\%20Application/Water\%20Supply\%20Report\%20Padma \%20Final.pdf (Accessed: 10 September 2020)

Corburn, J.; Agoe, V.; Asari, M.; Ortiz, J.; Patterson, R. with University of Nairobi, Muungano wa Wanavijiji, SDI Kenya, Akiba Mashinani Trust, Strathmore University, and Katiba Institute (2017). Mukuru, Nairobi: Situational Analysis. UC Berkeley, IURD [online] Available at: https://bit.ly/2wDzYMV (Accessed: 2 October 2020)

Dagdeviren, H.; Robertson, S.A. (2001) 'Access to Water in the Slums of Sub-Saharan Africa', Development Policy Review [online]. Available at: https://www.researchgate.net/publication/227371961_Access_to_Water_in_the_Slums_of_Sub -Saharan_Africa (Accessed: 12 September 2020)

Dovey, K.; King, R. (2011) 'Forms of Informality: Morphology and Visibility of Informal Settlements', Built Environment, 37 (1) [online]. Available at:

https://www.researchgate.net/publication/263381444_Forms_of_Informality_Morphology_and _Visibility_of_Informal_Settlements (Accessed: 5 October 2020)

Habitat III (2016) New Urban Agenda, United Nations Publications [online] Available at: www.habitat3.org (Accessed: 2 October 2020)

Kjellén, M. (2006) 'From Public Pipes to Private Hands Water Access and Distribution in Dar es Salaam, Tanzania', Department of Human Geography, Stockholm University. [online]. Available at: https://www.researchgate.net/publication/277822795_From_Public_Pipes_to_Private_Hands_ Water_Access_and_Distribution_in_Dar_es_Salaam_Tanzania(Accessed: 12 September 2020)

Matrix Development Consultants (1993) Nairobi's Informal Settlements: An Inventory Nairobi's, Office of Housing and Urban Programs, U.S. Agency for International Development.

Mitlin, D.; Walnycki, A. (2020) 'Informality as Experimentation: Water Utilities' Strategies for Cost Recovery and their Consequences for Universal Access', The Journal of Development Studies, 56:2, 259-277, [online]. Available at: https://www.tandfonline.com/doi/full/10.1080/00220388.2019.1577383(Accessed: 28 August 2020)

MMRDA (1996) Draft Development Plan for Mumbai Metropolitan Region, 1996-2011, Mumbai, Mumbai Metropolitan Region Development Authority. 
Murthy, S. (2012) 'Land security and the challenges of realizing the human right to water and sanitation in the slums of Mumbai, India' Health and Human Rights, 14/2 [online]. Available at: https://www.hhrjournal.org/2013/08/land-security-and-the-challenges-of-realizing-the-humanright-to-water-and-sanitation-in-the-slums-of-mumbai-india/ (Accessed: 2 October 2020)

Muungano wa Wanavijiji; Akiba Mashinani Trust (AMT) (2015) 'Improving Access to Justice and Basic Services in the Informal Settlements in Nairobi: an action research approach', Final technical report to the International Development Research Center.

Nairobi City Water and Sewerage Company (NCWSC) (2018). 'Water Act 2002, section 73(4) Regular tariff adjustment in ATHI Water Services Board (AWSB) area'. [online]. Available at: https://www.nairobiwater.co.ke/index.php/en/watertariffs (Accessed 10 September 2020)

Ono, H.; Kidokoro, T. (2020) 'Understanding the development patterns of informal settlements in Nairobi', Japan Architectural Review [online]. Available at: https://onlinelibrary.wiley.com/doi/abs/10.1002/2475-8876.12161 (Accessed: 1 August 2020)

Pamoja Trust (2009) An Inventory of the Slums in Nairobi. Nairobi.

Subbaraman, R.; Murthy, S. (2015). 'The right to water in the slums of Mumbai, India', Bulletin of the World Health Organisation 93(11):815-816 [online]. Available at: https://www.researchgate.net/publication/283349907_The_right_to_water_in_the_slums_of_ Mumbai_India (Accessed: 13 September 2020)

Subbaraman, R.; Shitole, S.; Shitole, T. (2013) 'The social ecology of water in a Mumbai slum: failures in water quality, quantity, and reliability'. BMC Public Health 13, 173. [online]. Available at: https://doi.org/10.1186/1471-2458-13-173 (Accessed: 8 October 2020)

UN-Habitat (2003) The Challenge of Slums, Global Report on Human Settlements 2003, Earthscan Publications Ltd.

UN-Habitat (2013b) Streets as public spaces and drivers of urban prosperity, Nairobi: UN-Habitat.

UN-Habitat (2016) Slum Almanac 2015/2016: tracking improvement in the lives of slum dwellers, United Nations Human Settlements Programme, Nairobi, Kenya.

United Nations (2020) Report of Secretary-General on the Work of the Organization, United Nations Publications.

United Nations (2015) 'Water for Life' 2005-2015, UN General Assembly.

World Health Organization (WHO); United Nations Children's Fund (UNICEF). (2017) 'Progress on drinking water, sanitation and hygiene: 2017 update and SDG baselines', Licence: CC BY-NC-SA 3.0 IGO. 